\title{
Correlation of Hormonal Profile and Lipid Levels with Female Adult Acne in a Tertiary Care Center of Nepal
}

\author{
Smriti Shrestha ${ }^{1}$ \\ 'Dhulikhel hospital, Kathmandu University, Dhulikhel, Kavre, Nepal.
}

\begin{abstract}
Background: Acne beyond 25 years of age is frequently associated with hormonal derangement in women. Hormonal association provides the impetus for hormonal therapy as well as underpins the need for blood investigations in this population. Hence, we aim to estimate the presence of hormonal derangement and lipid alteration in female adult acne.

Methods: A prospective, observational study was conducted in Dhulikhel Hospital from July 2015 to February 2016. Females older than 25 years with acne were taken in the study after informed consent. Total 100 patients were enrolled after sample size estimation. Hormonal paneland lipid profile were measured. Hormones tested were androgens, $\mathrm{C}$-peptide and thyroid stimulating hormone. Data analysis was done with SPSS-23. Bivariate analysis was done by chisquare test for categorical data.

Results: In this study, majority of patients were younger than 30 years $(70.5 \%)$ and perioral area most commonly involved. Hormonal alteration was seen in $37.2 \%$ patients, among which $17.9 \%$ had hyperandrogenism, $15.4 \%$ had abnormal thyroid level and $10.3 \%$ had high C-peptides respectively. Lipid profile was altered in $15.4 \%$ patients. Hormonal alteration had significant association with irregular menstruation $(\mathrm{P}<0.05)$ but not acne severity.

Conclusions: We observed hormonal alteration frequently in females with adult acne, which comprised of various hormonal parameters including hyperandrogenism. Hormonal alteration reflects deranged metabolic milieu and we suggest that wide hormonal panel should be done in female adult acne. Relationship of hormones with menstrual irregularity but not with acne severity, suggest that clinical symptoms should lead hormonal investigations in all grades of acne.

Keywords: Acne; adult; hormones; lipid; thyroid.
\end{abstract}

\section{INTRODUCTION}

Acne persisting or occurring after 25 years of age is adult acne or post-adolescent acne. ${ }^{1}$ With female predominance, it affects $12-22 \%$ women between 25 to 50 years age. ${ }^{2,3}$

Etiopathogenesis is multifactorial.Hormones implicated are androgens, estrogen, insulin, glucocorticoids, prolactin, etc. Hyperandrogenism(HA) can be ovarian or adrenal in women and Polycystic ovarian syndrome(PCOS) contributes to $>90 \%$ of such cases. ${ }^{4}$ Adult acne is frequently linked with hormonal alterations. ${ }^{4-7}$ Adult acne without hormonal imbalance, suggests end organ hypersensitivity to normal androgen levels. . $^{3,4}$

Since androgens are derived from plasma cholesterol, lipid alteration might cause acne. ${ }^{8}$ In adult acne, evidence for both deranged and normal lipid profile exists. ${ }^{9-11}$ Similarly, thyroid disorder may be related to acne. Acne comprises of $5 \%$ of skin changes in patients with thyroid disorder. ${ }^{12}$ However, thyroid changes in post-adolescent acne is controversial. ${ }^{13,14}$ Hence, this study was conducted to look for alteration in various hormonal parameters in female adult acne.

\section{METHODS}

A prospective, observational study was conducted in Department of Dermatology, Dhulikhel HospitalKathmandu University from July 2015 to February 2016.

Female patients older than 25 years, presenting with acne were included. Total of 100 patients were enrolled in the study. Sample size was calculated based on reported prevalence of approximately $50 \%$ of cases with 
Correlation of Hormonal Profile and Lipid Levels with Female Adult Acne

associated hormonal derangement in adult acne. ${ }^{5,6}$

$\mathrm{p}=0.5$ (probability), $\mathrm{q}=0.5(1-\mathrm{p})$, Allowable error $(\mathrm{d})=$ $20 \%$ of $p=0.1$, Sample size $=4 p q / d 2=100$

Clinico-epidemiological data was noted. Assessment of acne severity was based on grading the clinical morphology of lesions. ${ }^{15}$ All patients underwent investigations for androgens, insulin, thyroid and lipid levels. Blood was tested on the next day, early morning, on empty stomach and reports were collected same day.

Inclusion Criteria: Female patients 25 years of age or older, presenting with acne. Exclusion Criteria: Patients under treatment for acne, those with history of topical creams or cosmetics, contraceptives device usage, taking lipid lowering drugs, pregnancy, lactation, history of cardiovascular disease and history of smoking.

Parameters included were total testosterone(TT), sex hormone binding globulin (SHBG), Dihydroepiandrosterone sulfate(DHEAS), ratio of Leutinizing hormone(LH) to Follicle stimulating hormone(FSH), thyroid stimulating hormone(TSH), C-peptide and fasting lipid profile. $\mathrm{LH}: \mathrm{FSH}$ ratio of $>2: 1$ was considered abnormal. ${ }^{16}$ CLIA(chemiluminescent immunoassay) technique was used for hormonal measurement. CLIA is sensitive, automatable, fast and cheap. LIAISON ${ }^{\circledR}$ machine from DiaSorin brand was used. Standard laboratory values in Dhulikhel Hospital laboratory were taken as reference range. Lipid profile was estimated with dry chemistry analyzer. Cut off values for Dyslipidemia was taken according to National Cholesterol Education Program Adult Treatment Panel (NCEP ATP III) criteria. ${ }^{17}$

Approval from the Institutional Review Board was taken prior to the study. Informed consent was obtained from all patients. Data analysis was done with SPSS version 23. Bivariate analysis was done by chi-square for categorical data.

\section{RESULTS}

Among 100 patients enrolled, 78 patients (response rate $78 \%$ ) reported to us with results of blood investigations. The mean age of our patients was $28.8 \pm 3.64$ years, with the age range of 25-40 years. Majority of the patients (70.5\%) were between 25-29 years of age, and only $10.3 \%$ were older than 35 years. Duration of lesions varied from 3 weeks to 10 years. Persistent acne was seen in $55(70.5 \%)$ patients and late onset in $26(33.3 \%)$ patients. Table 1 given below shows descriptive analysis.

Among all, 64.1\% patients had acne grade II, followed by grade III (21.8\%), grade I(10.2\%) and grade IV(3.8\%) acne.
Perioral area and chin was most commonly involved (41\%). Other areas affected were cheeks, forehead, neck and trunk. Irregular menstrual cycle was seen in 24(30.8\%) patients.

\section{Table 1. Showing descriptive variables $(n=78)$.}

\begin{tabular}{|c|c|c|}
\hline Age & & \\
\hline $25-29$ years & 55 (70.5\%) & \multirow{2}{*}{$\begin{array}{l}\text { Mean }=28.28 \\
\text { years }\end{array}$} \\
\hline $30-34$ years & $15(19.2 \%)$ & \\
\hline $35-39$ years & $7(9.0 \%)$ & \multirow[t]{3}{*}{$S . D=3.64$} \\
\hline $40-45$ years & $1(1.3 \%)$ & \\
\hline \multicolumn{2}{|l|}{ Site } & \\
\hline Perioral & $32(41 \%)$ & \\
\hline $\begin{array}{l}\text { Upper face (cheeks } \\
\text { and forehead) }\end{array}$ & $31(39.7 \%)$ & \\
\hline Neck and trunk & $15(19.2 \%)$ & \\
\hline \multicolumn{3}{|l|}{ Severity of acne } \\
\hline Grade I & $8(10.3 \%)$ & \\
\hline Grade II & $50(64.1 \%)$ & \\
\hline Grade III & $17(21.8 \%)$ & \\
\hline Grade IV & $3(3.8 \%)$ & \\
\hline
\end{tabular}

\section{Table 2. Hormonal panel and lipid profile.}

Parameter No of Hyperan- Hormonal $(\mathrm{n}=78) \quad$ patients drogenism alteration (\%) with derangement

\begin{tabular}{lrrr}
\hline TT & $10(12.8 \%)$ & $14(17.9 \%)$ & 29 \\
SHBG & $4(5.1 \%)$ & & $(37.2 \%)$ \\
DHEAS & $1(1.3 \%)$ & & \\
LH:FSH & $8(10.2 \%)$ & & \\
ratio (>2:1) & & & \\
C-peptide & $8(10.3 \%)$ & & \\
TSH & $12(15.4 \%)$ & & \\
Lipid profile & $12(15.4 \%)$ & & \\
\hline
\end{tabular}
Hormonal alterations were noted in 29(37.2\%) patients(Table 2). Among them, hyperandrogenism was found in $14(17.9 \%)$ patients. Lipid alteration(15.4\%) comprised of increase in total cholesterol( $\mathrm{TC}=7.6 \%)$, Low density lipoproteins ( $L D L=3.8 \%)$, triglycerides $(T G=5.1 \%)$ and decrease in high density lipoproteins $(\mathrm{HDL}=10.2 \%)$. Some patients had abnormal levels of more than one biochemical parameter. Table 2 shows frequency of patients with abnormal blood parameters. Menstrual irregularity had statistically significant association with hormonal alteration ( $\mathrm{P}=0.038)$ (Table 3$)$, but not with hyperandrogenism (Table 4). Hormonal derangement or hyperandrogenism was not associated with severe acne (Table 5, Table 6). 


\begin{tabular}{|c|c|c|c|c|}
\hline \multirow{2}{*}{$\begin{array}{l}\text { Hormones } \\
(\mathrm{n}=78)\end{array}$} & \multicolumn{2}{|r|}{ Menses } & \multirow[t]{2}{*}{ Total } & \multirow[t]{2}{*}{$P$ value } \\
\hline & Regular & Irregular & & \\
\hline Normal & 38 & 11 & 49 & \multirow[b]{3}{*}{0.038} \\
\hline Altered & 16 & 13 & 29 & \\
\hline Total & 54 & 24 & 78 & \\
\hline
\end{tabular}

\begin{tabular}{|c|c|c|c|c|}
\hline \multirow{2}{*}{$\begin{array}{l}\text { Hyperandrogen- } \\
\text { ism }(n=78)\end{array}$} & \multicolumn{2}{|l|}{ Menses } & \multirow[t]{2}{*}{ Total } & \multirow[t]{2}{*}{$P$ value } \\
\hline & Regular & Irregular & & \\
\hline Absent & 46 & 18 & 64 & \multirow[b]{3}{*}{0.28} \\
\hline Present & 8 & 6 & 14 & \\
\hline Total & 54 & 24 & 78 & \\
\hline
\end{tabular}

Table 5. Hormones and acne severity

\begin{tabular}{|c|c|c|c|c|c|c|}
\hline \multirow{2}{*}{$\begin{array}{l}\text { Hormone } \\
(n=78)\end{array}$} & \multicolumn{4}{|c|}{ Acne Severity (Grade) } & \multirow[t]{2}{*}{ Total } & \multirow[t]{2}{*}{$P$ value } \\
\hline & 1 & II & III & IV & & \\
\hline Normal & 7 & 34 & 7 & 1 & 64 & \multirow[b]{3}{*}{0.066} \\
\hline Altered & $1(12.5 \%)$ & $16(32 \%)$ & $10(58.8 \%)$ & $2(66.7 \%)$ & 14 & \\
\hline Total & 8 & 50 & 17 & 3 & 78 & \\
\hline
\end{tabular}

\begin{tabular}{|c|c|c|c|c|c|c|}
\hline \multirow{2}{*}{$\begin{array}{l}\text { Hyperandrogenism } \\
(\mathrm{n}=78)\end{array}$} & & & \multicolumn{2}{|c|}{ Acne Severity (Grade) } & \multirow[t]{2}{*}{ Total } & \multirow[t]{2}{*}{$P$ value } \\
\hline & I & II & III & IV & & \\
\hline Absent & 7 & 44 & 11 & 2 & 64 & \multirow[b]{3}{*}{0.15} \\
\hline Present & $1(12.5 \%)$ & $6(12 \%)$ & $6(35.3 \%)$ & $1(33.3 \%)$ & 14 & \\
\hline Total & 8 & 50 & 17 & 3 & 78 & \\
\hline
\end{tabular}

\section{DISCUSSION}

Acne is a disorder of adolescents. However, its prevalence among post-adolescent population is rising. Studies report adult acne in up to $60 \%$ of patients, with $10 \%$ patients between 35 to 44 years of age..$^{1,3}$

The mean age of the patients in our study was $28.8 \pm 3.64$ years, slightly younger than previous reports with mean of 30-35.5 years. ${ }^{1,6-18}$ Adult acne is persistent or late onset. Persistent acne is continuation of adolescent acne beyond 25 years of age, while late onset acne begins after 25 years. ${ }^{18}$ In our study, persistent acne occurred in $70.5 \%$ cases and late onset in $33.3 \%$ patients, consistent with previous findings. ${ }^{7,18}$ Goulden et al. suggested that true late onset acne may represent abnormal androgen metabolism. ${ }^{1}$ Sporadic acne and recurrent acne have also been described but their association with hormones is ill-defined. ${ }^{7}$ Premenstrual flare is common in adult acne, seen in $44-78 \%$ cases. ${ }^{19,20}$ Older women (>33 years) report premenstrual flare more than $22-33$ years old. ${ }^{20}$ We haven't noted entities like premenstrual flare or recurrent acne.

Skin lesions in adult acne commonly occur in perioral and lower face distribution. ${ }^{1,18-21}$ In our study, commonest site was lower face $(41 \%)$ while Khunger et al. found commonest involvement of cheeks(81\%) followed by lower face. ${ }^{18}$ Morphology of adult acne is inflammatory and low grade, while adolescent acne is comedonal.
In accordance, our study had grade II acne(64.1\%) in majority of the patients. ${ }^{1,8,18}$ Capitanio et al. reported predominantly comedonal morphology in adult acne with strong correlation with smoking. ${ }^{21}$

Factors affecting female adult acne are family history, smoking, cosmetics, obesity, hormones, stress, diet, etc. 1,21,22 Androgens are key hormones regulating sebum production and follicular hyperkeratosis. Androgeninsensitive individuals do not produce sebum and do not develop acne. LH regulates androgen secretion by ovaries. Estrogen decreases sebaceous gland size and sebum production. ${ }^{3,4}$ While androgens have clear roles in acne pathogenesis, research continues on the role of estrogen.

Insulin directly stimulate sebocyte proliferation, increase androgens, inhibit SHBG, stimulate 5 a reductase enzyme and enhance lipogenesis. It increases insulin like growth factors(IGF-1), which alter androgens as well as keratinocyte proliferation. Hence both insulin and IGF-1 have comedogenic effect. ${ }^{4,23}$ Likewise, cholesterol is a precursor of androgens, rise in total cholesterol is linked with acne. Androgens in turn, increase hepatic lipase activity, thus increasing HDL catabolism. ${ }^{10}$ Furthermore, insulinotropic palaeolithic diets are extrinsic factors for insulin resistance leading to acne. ${ }^{22,23}$

Hyperandrogenism, insulin resistance and thyroid disorders positively correlate with adult acne, and also 
independently with each other. Dyslipidemia is closely linked insulin resistance and hypothyroidism..$^{3,4,23}$ PCOS is commonest endocrine disorder in women, with mild elevation of testosterone, hyperinsulinemia, dyslipidemia and elevated LH:FSH ratio. ${ }^{24}$ There is low grade chronic inflammation, propagating a vicious cycle of hormonal imbalance and acne in these patients. ${ }^{8}$

In view of role of hormones, review articles suggest a wide hormonal panel tests in female adult acne, but most studies are based on androgen profile..$^{3,4,7}$ Others have included endocrine parameters such as prolactin, estradiol, progesterone, serum cortisol, insulin and thyroid antibodies. ${ }^{9,10}$ There is no standard protocol for hormonal profile yet. Hormonal evaluation is indicated in those with late onset or persistent acne, menstrual irregularity, clinical signs of androgen excess or resistant to therapy. ${ }^{4,7}$

In our study, hormonal alteration occurred in $37.2 \%$ patients and hyperandrogenism in $17.9 \%$ patients. Addor et al had hormonal alteration in $49.7 \%$ of their patients. ${ }^{6}$ HA was seen in $28.6 \%-70 \%$ patients with acne. ${ }^{5,10}$ Khunger et al. from India had hyperandrogenism in only $3.04 \%$ of their patients. They found altered TT, LH:FSH ratio, increased insulin but no change in DHEAS or SHBG similar to our study. ${ }^{18}$ Others show elevated TT and DHEAS in adult acne. There are reports with normal or "highnormal" levels of TT and DHEAS as well. Levels of SHBG are inconsistent, with raised, normal or decreased levels in different studies. ${ }^{10,25}$ This lack of consistency in prevalence and pattern of hyperandrogenism in adult acne is probably because of external triggers described earlier and different clinical profile of patients in these studies. Acne in patients with hirsutism, obesity and irregular menstrual cycle had more evidence of hyperandrogenism. 5,9,26 In our study, there was significant association of menstrual irregularity with altered hormonal profile $(\mathrm{P}<0.05)$, while its association with hyperandrogenism was not significant. Severity of acne was not associated with hyperandrogenism or total hormonal profile as reported by Cibula et al. ${ }^{27}$

Lipid profile was altered in $15.4 \%$ of our patients, with low HDL(10.2\%) as the commonest derangement. Studies show alteration of lipid profile in acne similar to PCOS, with rise in TC and LDL and decrease in HDL. ${ }^{8,9}$ Lipid alteration has also been noted in non-obese, non-hirsute acne patients, but there are reports with normal lipid profile in acne. ${ }^{10,11} \mathrm{It}$ is important to look for other risk factors such as diet, obesity or coexisting illness before determining casual association of lipid profile with adult acne.
In our study, C-peptide was altered in $10.3 \%$ patients. $\mathrm{C}$-peptide is a measure of endogenous insulin secretion and is more stable than insulin. ${ }^{28}$ Although insulin is indirectly associated with acne as described earlier, Balta et. al did not find its major role in the pathogenesis of adult acne. ${ }^{29}$ Another study showed insulin resistance common in male postadolescent acne. ${ }^{30}$ Hence, data is not conclusive so far, but our study provides an impetus for future research.

TSH was altered in $15.4 \%$ of our patients. While Vergou et al. found significant correlation of thyroid antibodies with adult acne, Ekiz et al. reported no association with thyroid profile. ${ }^{13,14}$ Since percentage alteration in TSH is comparable with HA and lipid levels in our study, we suggest TSH be included among screening tests.

It is noteworthy that screening for thyroid and insulin resistance besides androgens, doubled the frequency of hormonal alteration in our study. Moreover, wider hormonal panel advised in literature is not included in our study, which would perhaps detect wider endocrine abnormalities. Moreoever, we had not enrolled healthy age matched controls to compare their hormonal profile with, which is a limitation of this study.

\section{CONCLUSIONS}

Role of hormones in adult acne has been reiterated in time. However, there is no strict consensus or guidelines yet. Although recent reviews on adult acne doesn't strictly require hormonal alteration in order to start hormonal therapy, biochemical evidence of hormonal derangement can guide the line of treatment. We observed hormonal alteration frequently in females with adult acne, which comprised of various hormonal changes besides hyperandrogenism. Hence we suggest that a wide array of hormonal alteration might lead to adult acne. Moreover, relationship of hormones with menstrual irregularity but not with acne severity, suggest that clinical symptoms should lead hormonal investigations in all grades of acne. We suggest that dermatologists should consider hormonal alterations in patients with acne persisting after 25 years of age, especially in women.

\section{ACKNOWLEDGEMENTS}

I want to thank Dr Dipesh Tamrakar (MD) for his relentless guidance during statistical analysis of the given study. I deeply appreciate his support during research proposal writing as well as completing the original article. 


\section{REFERENCES}

1. Goulden V, Clark S, Cunliffe W. Post-adolescent acne: a review of clinical features. Br J Dermatol 1997;136:6670.[PMID]

2. Collier C, Harper J, Cantrell W, et al. The prevalence of acne in adults 20 years and older. J Am Acad Dermatol. 2008;58:56-59.[PMID]

3. Trivedi MK, Shinkai K, Murase JE. A review of hormonebased therapies to treat adult acne vulgaris in women. Int J Womens Dermatol. 2017;3(1):44-52. [DOI]

4. Elsaie ML. Hormonal treatment of acne vulgaris: an update. Clin Cosmet Investig Dermatol. 2016; 9: 241248. [PMCID]

5. Seirafi H, Farnaghi F, Vasheghani-Farahani A, et al. Assessment of androgens in women with adult-onset acne. Int J Dermatol. 2007;46:1188-1191. [PMID]

6. Addor FA, Schalka S. Acne in adult women: epidemiological, diagnostic and therapeutic aspects. An Bras Dermatol. 2010 Nov-Dec;85(6):789-95. [PMID]

7. Zeichner JA, Baldwin HE, Cook-Bolden FE, Eichenfield LF,Friedlander SF, Rodriguez DA. Emerging Issues in Adult Female Acne. J Clin Aesthet Dermatol. 2017 Jan;10(1):37-46. [PMID]

8. Da Cunha MG, Batista ALF, Macedo MS, Machado Filho CDS, Fonseca FLA. Study of lipid profile in adult women with acne. Clin Cosmet Investig Dermatol. 2015;8:449. 454. [PMCID]

9. Abulnaja KO. Changes in the hormone and lipid profile of obese adolescent Saudi females with acne vulgaris. Braz J Med Biol Res. 2009;42:501-5. [PMID]

10. Bakry OA, El Shazly RMA, El Farargy SM, Kotb D. Role of hormones and blood lipids in the pathogenesis of acne vulgaris in non-obese, non-hirsute females. Indian Dermatol Online J. 2014;5(Suppl 1):S9-S16. [DOI]

11. Akawi ZE, Latif NA, Razzak KA, Aboosi MA. The relationship between blood lipid profile and acne. J Health Sci. 2007;53:596-9.[FullText]

12. ArtantaŞ S, Gul U, Kiliç A, Guler S. Skin findings in thyroid diseases. Eur J Intern Med. 2009 Mar;20(2):15861.[PMID]

13. Vergou T, Mantzou E, Tseke P, Moustou AE, Katsambas A, Alevizaki M, et al. Association of thyroid autoimmunity with acne in adult women. J Eur Acad Dermatol Venereol. 2012 Apr;26(4):413-6.[PMID]

14. Ekiz O, Balta I, Unlu E, Bulbul SB, Rifaioğlu EN, Dogramaci AC. Assessment of thyroid function and lipid profile in patients with postadolescent acne in a Mediterranean population from Turkey. Int J Dermatol. 2015 Dec;54(12):1376-81. [PMID]

15. Witkowski JA, Parish LC. The assessment of acne: An evaluation of grading and lesion counting in the measurement of acne. Clin Dermatol. 2004;22:394-7. [PMID]

16. Sheehan MT. Polycystic Ovarian Syndrome: Diagnosis and Management. Clin Med Res. 2004 Feb;2(1):13-27. [PMID]

17. Executive Summary of the Third Report of The National Cholesterol Education Program (NCEP) Expert Panel on Detection, Evaluation, And Treatment of High Blood Cholesterol In Adults (Adult Treatment Panel III). Expert Panel on Detection, Evaluation, and Treatment of High Blood Cholesterol in Adults. JAMA. 2001 May; 285(19):2486-97.[PMID]

18. Khunger N, Kumar C. A clinico-epidemiological study of adult acne: Is it different from adolescent acne? Indian J Dermatol Venereol Leprol. 2012;78:335-41. [DOI]

19. Poli F, Dreno B, Verschoore M. An epidemiological study of acne in female adults: results of a survey conducted in France. J Eur Acad Dermatol Venereol. 2001 Nov; 15(6):541-5. [PMID]

20. Stoll S, Shalita AR, Webster GF, Kaplan R, Danesh S, Penstein A. The effect of the menstrual cycle on acne. J Am Acad Dermatol. 2001;45:957-960. [PMID]

21. Capitanio B, Sinagra JL, Bordignon V, Cordiali FP, Picardo M, Zouboulis CC. Underestimated clinical features of postadolescent acne. J Am Acad Dermatol. 2010 Nov;63(5):782-8.[DOI]

22. Cordain L, Lindeberg S, Hurtado M, Hill K, Eaton SB, Brand-Miller J. Acne vulgaris: a disease of Western civilization. Arch Dermatol. 2002 Dec; 138(12):1584-90. [PMID]

23. Emiroğlu N, Cengiz FP, Kemeriz F. Insulin resistance in severe acne vulgaris. Advances in Dermatology and Allergology/Postȩpy Dermatologii i Alergologii. 2015;32(4):281-285. [PMCID]

24. Fauser BC, Tarlatzis BC, Rebar RW, Legro RS, Balen AH, Lo bo R, et al. Consensus on women's health aspects of polycystic ovary syndrome (PCOS): the Amsterdam ESHRE/ASRM-Sponsored 3rd PCOS Consensus Workshop Group. 2012 Jan;97(1):28-38.e25. [PMID]

25. Da Cunha MG, Fonseca FL, Machado CD. Androgenic hormone profile of adult women with acne. Dermatology. 2013;226(2):167-71. [PMID]

26. Alan S, Cenesizoglu E. Effects of hyperandrogenism and high body mass index on acne severity in women. Saudi 
Med J. 2014 Aug;35(8):886-9. [PMID]

27. Cibula D, Hill M, Vohradnikova O, Kuzel D, Fanta M, Zivny $\mathrm{J}$. The role of androgens in determining acne severity in adult women.Br J Dermatol. 2000 Aug;143(2):399-404. [PMID]

28. Jones AG, Hattersley AT. The clinical utility of C-peptide measurement in the care of patients with diabetes. Diabetic Medicine. 2013;30(7):803-817. [PMID]
29. Balta I, Ekiz O, Ozuguz P, Ustun I, Karaca S, Dogruk KS, et al. Insulin resistance in patients with post-adolescent acne. Int J Dermatol. 2015;54(6):662-6. [PMID]

30. Nagpal M, De D, Handa S, Pal A, Sachdeva N. Insulin resistance and metabolic syndrome in young men with acne. JAMA Dermatol. 2016;152(4):399-404. [PMID] 